\title{
COMPARISON OF FLOWER-VISITING BEHAVIOUR OF BUMBLEBEES AND SWALLOWTAIL BUTTERFLIES TO THE JAPANESE AZALEA (RHODODENDRON JAPONICUM)
}

\author{
Keigo Takahashi ${ }^{*}$, Takao Itino ${ }^{2,3}$ \\ ${ }^{1}$ Graduate School of Science and Technology, \\ ${ }^{2}$ Department of Biology, Faculty of Science and \\ ${ }^{3}$ Institute of Mountain Science, Shinshu University, Matsumoto, Nagano 390-8621, Japan
}

\begin{abstract}
Examination of the efficacy of pollinators that are not morphologically matched to a flower's shape can deepen our understanding of the main pollinators of a plant species. In central Japan, Rhododendron japonicum is visited much more frequently by bumblebees than by butterflies although its flower shape is more suited for pollination by large butterflies. Here, we observed flower-visiting behaviour of Bombus diversus queens and the alpine black swallowtail butterfly, Papilio maackii, and compared their efficacy as pollinators. Papilio maackii always touched the stigma during a flower visit, whereas $B$. diversus queens did so during just $54 \%$ of their flower visits. As bumblebees visit neighboring flowers of a $R$. japonicum tree in sequence not like $P$. maackii, we hypothesized that they deliver self pollen to $R$. japonicum so that the fruit set would be low. However, the fruit set in a bumblebee-dominated area was $72.5 \%$, significantly higher than that by hand-pollination with self pollen (3I.4\%). This suggests that $R$. japonicum can obtain sufficient fruits by $B$. diversus queens although its flower shape morphologically matches to pollination by swallowtail butterflies.
\end{abstract}

Keywords: bumblebees, flower shape, pollination, rhododendron, swallowtail butterflies

\section{INTRODUCTION}

Morphological matches of flower shape to primary pollinators have been an essential topic in evolutionary biology of pollination (Nilsson 1988; Stang et al. 2009; Newman 2013). Most plant species are visited by many kinds of animals in nature (Herrera 1987; Waser et al. 1996), including flower-visitors whose body shapes are not suited to the pollen deposition (Javorek et al. 2002; Fumero-Cabán \& Meléndez-Ackerman 2007). For example, Epps et al. (2015) found that the flame azalea, Rhododendron calendulaceum (Michaux) Torrey, is only pollinated by morphologically matching large butterflies but not by frequent-flower visiting bees. It is, however, still unclear to what extent such morphologically mismatching pollinators contribute to plant pollination.

The angiosperm genus Rhododendron (Ericaceae) comprises more than I,000 species (Chamberlain et al. I996). Some Rhododendron species with small flowers (corolla diameter $1.5-3.0 \mathrm{~cm}$ ) are pollinated by bumblebees or honeybees (Escaravage \& Wagner 2004; Ono et al. 2008; Kudo et al. 20II), whereas those with large flowers (corolla diameter 5-7 cm) sometimes depend on swallowtail butterflies and birds for pollination (Epps et al. 2015; Huang et al. 2017). On the other hand, $R$. ponticum (corolla

Received I5 November 2019, accepted I5 June 2020

*Corresponding author: kII2I0102088@gmail.com diameter up to $6 \mathrm{~cm}$ ) is mainly pollinated by bumblebees (Mejias et al. 2002; Stout 2007), and 38.6\% of visits by bumblebees led to contact with stigmas (Stout 2007). This indicates that bumblebees can deliver pollen even in Rhododendron species with large flowers.

Sixty-seven Rhododendron species have been confirmed in Japan (Yamazaki 1996). Rhododendron japonicum (A. Gray) Suringer (subgenus Hymenanthes, section Pentanthera) is a deciduous shrub distributed from Honshu to Kyushu, Japan (Yamazaki 1996). A single shrub of $R$. japonicum can have from 20 to 3,000 flowers. Flower lifespan is 7-9 days (K.T., personal observation). Similar to Rhododendron species pollinated by butterflies in Malesia (Stevens I985), $R$. japonicum has large orange flowers (corolla diameter $69.5 \mathrm{~mm}$ on average; Takahashi \& Itino 2017). Pollen grains of $R$. japonicum have strong viscosity, and $R$. japonicum has a close relative, $R$. calendulaceum that is pollinated by swallowtail butterflies (Goetsch et al. 2005; Epps et al. 2015). All of these characteristics suggest that $R$. japonicum may be pollinated by butterflies.

In our study area in Nagano, Japan, however, the visitation frequency of bumblebees (mainly the queens of Bombus diversus Smith) to $R$. japonicum is much higher than that of butterflies (mainly the swallowtail butterfly Papilio maackii Ménétriès; Takahashi \& Itino 2017). The first aim of this study is to investigate whether the bumblebees and butterflies both touch the stigma during flower visits or not. Secondly, bumblebees tend to visit neighboring flowers on the same shrub in sequence, which may lead to self-pollination (De 
Jong et al. 1993). As many Rhododendron species are selfincompatible or only weakly self-compatible ( $\mathrm{Ng} \&$ Corlett 2000; Kudo et al. 20II), bumblebees may not be ideal pollinators of Rhododendron species because they facilitate self-pollination. We previously found that queens of $B$. diversus tend to spend more than 10 min visiting a large $R$. japonicum shrub (Takahashi \& Itino 2017). Thus, if $R$. japonicum is self-incompatible, then it could be viewed to improve the pollination effect of bumblebees that make self pollen deposition inevitable. Thirdly, if the visiting frequency of bumblebees to Rhododendron flowers is very high, then they can potentially function as pollinator.

The goal of this study was to determine whether $B$. diversus queens worked as the pollinator of $R$. japonicum in our study area. Accordingly, we conducted field observations and a breeding system experiment to answer the following three questions. (I) Are B. diversus queens inferior to $P$. maackii in the frequency with which they deliver $R$. japonicum pollen during a flower visit? (2) Is $R$. japonicum selfincompatible or self-compatible? (3) Can the basically selfincompatible $R$. japonicum achieve enough fruit set at sites where the sequentially flower-visiting bumblebees predominantly visit flowers?

\section{MATERIALS AND METHODS}

\section{Study site}

This study was conducted in Norikura $\left(36^{\circ} 07^{\prime} \mathrm{N}\right.$, I37³7’E; I,480 m a.s.1.), Matsumoto, Nagano, central Japan, from 31 May to 6 July 2017, a period which encompasses the whole flowering season of $R$. japonicum. At our study site in Norikura, 200-300 R. japonicum plants grow in patches over a distance of about $\mathrm{I} \mathrm{km}$ along the edge of a mixed forest dominated by Quercus crispula Blume and Malus sieboldit (Regel) Rehder. We conducted field observations and a breeding system experiment at the study site.

\section{Sequential flower-visiting and geitonogamous pollen deposition}

To compare sequential flower-visiting of the same plant between the bumblebee ( $B$. diversus), and the butterfly ( $P$. maackii), we investigated the number of flowers each species visited in sequence. We recorded videos of $B$. diversus queens visiting $R$. japonicum flowers on the selected shrub with a digital camera (SONY, DSC-TX30) from I2:55 to I3:00 on II June and from II:00 to I3:00 on I2, I4 and I7 June 2017. We began recording a video as soon as a bumblebee began visiting the plant and continued recording while the bumblebee visited flowers on that plant. We also counted the number of flowers visited by the bumblebee in sequence. When a butterfly visited a shrub, we observed its behaviour and also recorded the number of flowers on the plant that it visited in sequence ( $4 \mathrm{~h}$ per day for a total of $40 \mathrm{~h}$ ). To compare flower visiting frequency and number of sequential visits to flowers on the same plant between $B$. diversus and $P$. maackii, we used the Wilcoxon rank sum test in $\mathrm{R}$ version 3.4.0 software ( $\mathrm{R}$ core team 20I7).

Insect body contacts with the anthers and stigma during flower visits
We used data from the videos described above to determine the frequency with which the body of the $B$. diversus queens (dorsal thorax, lateral thorax, ventral abdomen, or other parts) touched the stigma or anthers of a flower during flower visits (i.e., the number of flower visits during which the bumblebee touched the stigma or anthers relative to the total number of bumblebee flower visits, expressed as a percentage). Flower-visiting insects cannot access nectar unless they insert their proboscises into the nectar tube of the upper petal of $R$. japonicum. Although $P$. maackii suck nectar in correct (front) position, $B$. diversus queens suck nectar in various positions (Fig. I). To investigate the relative body size of bumblebees in relation to flower size, we measured body length and abdomen width of $B$. diversus queens narcotized with $\mathrm{CO}_{2}$. When $P$. maackii visited a shrub during the flower visitor observations, we also recorded whether it touched the anthers or stigma of each visited flower. We used Fisher's exact test in $R$ version 3.4.0 software ( $R$ core team 2017) to evaluate the difference in frequency of contact with the flower stigma or anthers between $P$. maackii butterflies and $B$. diversus queens.

\section{Breeding system experiment}

To ascertain the degree of self-compatibility, we conducted an experiment comprising four hand-pollination treatments by using bagged flowers: (I) self: mature anthers from a flower were rubbed against the stigma of the same flower; (2) outcross: mature anthers from a flower were rubbed against the stigma of a flower on another plant located at least $10 \mathrm{~m}$ from the donor plant; (3) mixed: the entire surface of the stigma was hand-pollinated with self pollen from the same flower, and then the stigma was immediately hand-pollinated with outcross pollen from a flower on another plant at least $10 \mathrm{~m}$ away; (4) time-lag: half of the stigma's surface was hand-pollinated with self pollen and then $3 \mathrm{~d}$ later, the other half was hand-pollinated with outcross pollen. It was not difficult to hand-pollinate the two halves of the stigma separately with self pollen and outcross pollen because the $R$. japonicum stigma is large (diameter I.56 \pm $0.03 \mathrm{~mm}$, mean \pm S.E., $N=40$ ). Treatments (3) and (4) were designed to imitate pollination conditions by bumblebees in the wild.

For this experiment, we haphazardly selected $40 R$. japonicum shrubs along the edge of a mixed forest and bagged two different inflorescences per plant (each with 3-8 flower buds) with white nylon nets. Two flowers of the first inflorescence were used for the self and outcross treatments, and two flowers of the second inflorescence were used for the mixed and time-lag treatments. Other flowers of the inflorescences and unnecessary anthers of the target flowers were removed before the experiments.

In addition, an unbagged flower was selected from each of the 40 plants and assigned to an "open area". The 40 plants varied in the number of flowers and tree height. We estimated the visitation frequency of $B$. diversus queens in the open area flowers by a line transect census (one route, I km long, $4 \mathrm{~m}$ wide). We counted the number of queens that visited open area flowers during 09:00 to II:00 local time on I2, I4 and 17 June. Flowers in the bumblebee-dominated area (see below) were excluded from this census. 

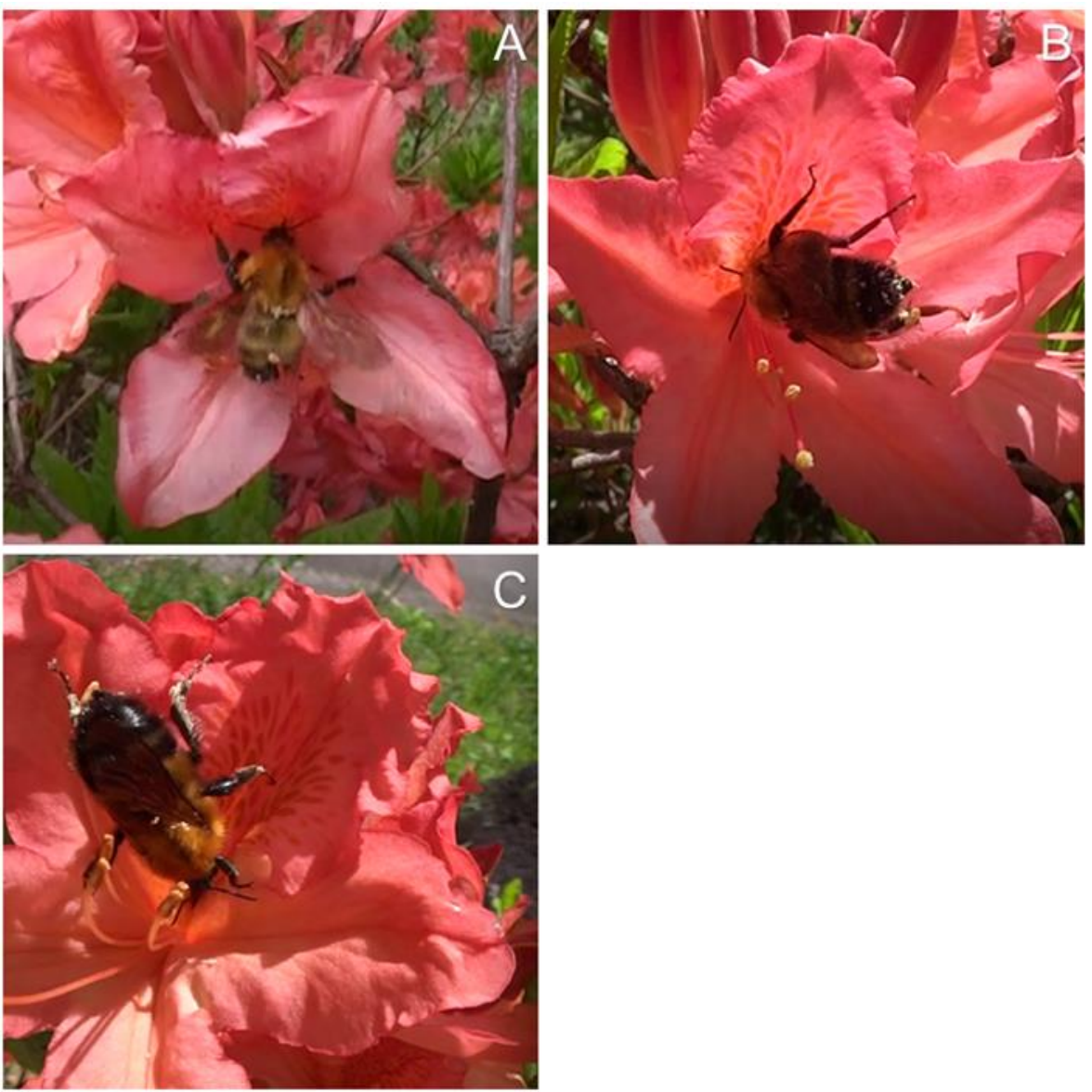

FiguRE I. Rhododendron japonicum flowers and nectarsucking postures of Bombus diversus queens. (A) front position. (B) side position. (C) inverted position.

We also haphazardly selected 40 flowers on four $R$. japonicum shrubs located in an area where a lot of $B$. diversus queens but no $P$. maackii butterflies were observed and assigned them to a "bumblebee-dominated area". Each of the four plants had more than I,000 flowers during the peak flowering period. We used the data from the video recordings described above to count the number of queens that visited the bumblebee-dominated area flowers.

We checked the fruit sets of each treatment on 17 August, and compared the fruit sets between treatments and areas by using Fisher's exact test with Holm correction (R Core Team 2017).

\section{RESULTS}

\section{Sequential flower-visiting and geitonogamous pollen deposition}

On average, a $B$. diversus queen visited $17.8 \pm 2.3$ flowers in sequence during a visit to a single plant (mean \pm S.E., the number of insects $=30$, the number of flowers $=534$, range 2-44 flowers), whereas a $P$. maackii individual visited $3.2 \pm$ I.5 flowers in sequence during a visit to a single plant (the number of insects $=9$, the number of flowers $=29$, range $I-$ I5 flowers). The $B$. diversus queens visited significantly more flowers in sequence during a visit to a single plant than $P$. maackii individuals $\operatorname{did}\left(W=248, P=3.2 \times 10^{-5}\right)$.

\section{Insect body contacts with the anthers and stigma during flower visits}

During $R$. japonicum flower visits, $P$. maackii more likely touched the stigmas than $B$. diversus queens $\left(P=3.2 \times 10^{-7}\right.$; Tab. I), but no significant difference in the frequency of touches to anthers $(P=0.06$; Tab. I). To suck nectar from an $R$. japonicum flower, the butterfly always faced the upper sides of the petals, so its body and/or wings rubbed against the stigma and anthers. In contrast, B. diversus queens (body length $22.7 \pm 0.3 \mathrm{~mm}$, abdomen width $9.7 \pm 0.1 \mathrm{~mm}$; mean \pm S.E, $N=22$ ) entered the flower from various directions and adopted various postures to suck the nectar; as a result, they did not always come into contact with the stigma (Fig. I). The queens were putting together pollen in the pollen baskets on their legs, but none of them intentionally rubbed anthers with forelimbs

\section{Breeding system experiment}

Fruit set of $R$. japonicum in the self treatment (31.4\%) was significantly lower than that in the outcross treatment $\left(88.6 \% ; P=2.5 \times 10^{-5} ;\right.$ Fig. 2$)$, indicating that $R$. japonicum is weakly self-compatible in our study area. Fruit set was $54.1 \%$ in the mixed treatment and $55.6 \%$ in the time-lag treatment; in both of these treatments, fruit set was significantly lower than that in the outcross treatment (outcross vs. mixed: $P=0.02$; outcross vs. time-lag: $P=0.04$; Fig. 2) indicating the adverse effect of self pollen. 
TABLE I. Percentage of Rhododendron japonicum flowers of which the anthers or stigma were touched by the visiting Bombus diversus or Papilio maackii. The difference in contact frequency between $P$. maackii and $B$. diversus queens was tested by Fisher's exact test: n.s., not significant; $P<1.0 \times 10^{-6}$.

Percentage of $R$. japonicum flowers contacted by insects

number of flower visits with contact / total number of insect flower visits)

\begin{tabular}{|c|c|c|c|c|c|}
\hline & & Anthers & & Stigma & \\
\hline \multirow{5}{*}{ Bombus diversus } & Dorsal thorax & $16.7 \%(52 / 311)$ & & $9.0 \%(28 / 311)$ & \\
\hline & Lateral thorax & $24.8 \%(77 / 311)$ & & $5.1 \%(16 / 311)$ & \\
\hline & Ventral abdomen & $44.7 \%(139 / 311)$ & & $26.7 \%(83 / 311)$ & \\
\hline & Other parts & $32.2 \%(100 / 311)$ & & $19.0 \%(59 / 311)$ & \\
\hline & Total & $87.8 \%(273 / 311)$ & & $54.0 \%(168 / 311)$ & \\
\hline Papilio maackii & $\begin{array}{l}\text { Wings, ventral thorax, } \\
\text { and abdomen }\end{array}$ & $100 \%(26 / 26)$ & & $100 \%(26 / 26)$ & **** \\
\hline
\end{tabular}

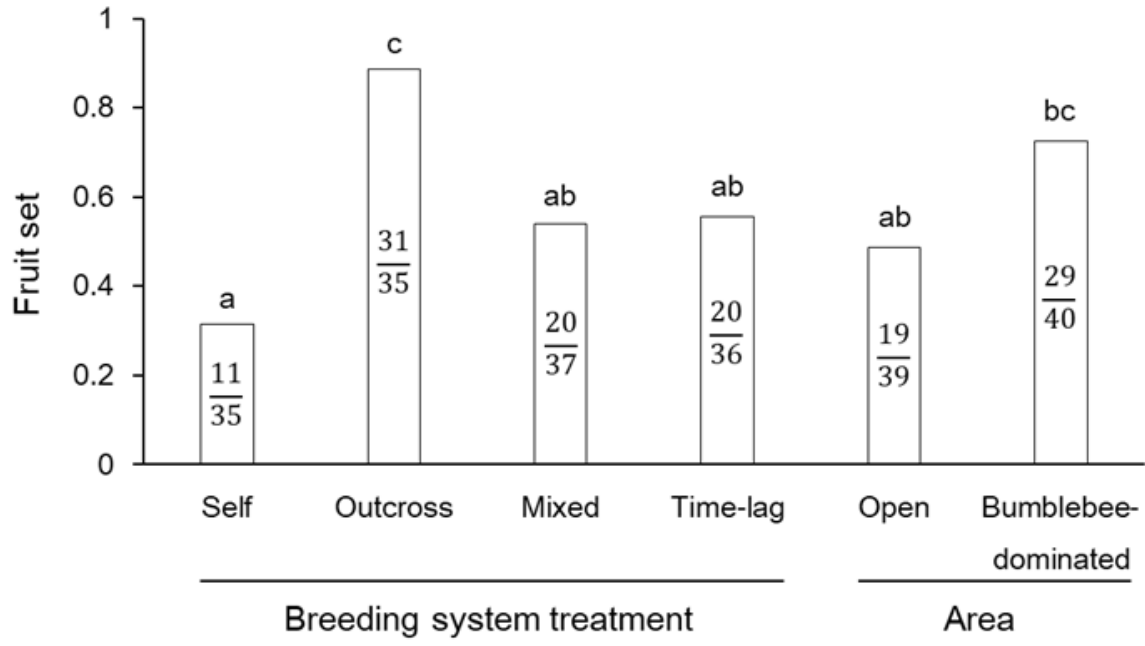

FIGURE 2. Fruit set in the Rhododendron japonicum.

We observed six $B$. diversus queens visiting open area flowers during the 6-h line census, whereas during the 6-h census in the bumblebee-dominated area, we observed 30 queens visiting flowers. Fruit set in the open area was $48.7 \%$ and that in the bumblebee-dominated area was $72.5 \%$ (Fig. $2)$. Fruit set in the bumblebee-dominated area was significantly higher than that in the self treatment $(P=0.007$; Fig. 2) indicating the possibility that $B$. diversus queens delivered outcross pollen to the stigmas of $R$. japonicum, at least in the area where they were abundantly observed.

\section{DISCUSSION}

Bombus diversus queens were less likely to touch the stigma during a flower visit, compared with $P$. maackii (Tab. I). Thus, the answer of our question (I) in the introduction (Are $B$. diversus queens inferior to $P$. maackii in the frequency with which they deliver $R$. japonicum pollen during a flower visit?) was "yes". However, as the visitation frequency of bumblebees was about ten times higher than that of swallowtail butterflies in this study site (Takahashi \& Itino 2017), B. diversus may exceed $P$. maackii in the chance of pollen delivery. Such a visitation of bumblebees to Rhododendron flowers with fewer contacts with stigmas than butterflies was also reported in the interaction between $R$. ponticum with large flowers and large bumblebees (Stout 2007). On the other hand, $R$. calendulaceum with large flowers are pollinated by butterfly wings (Epps et al. 20I5). Looking at the flower shape, the very long stamens and pistils of $R$. calendulaceum may account for this difference.

Regarding our question (2) in the introduction (Is $R$. japonicum self-incompatible or self-compatible?), $R$. japonicum was weakly self-compatible (Fig. 2). However, resource allocation by the maternal plant may have influenced the results of our experimental manipulation. If a maternal plant shunts more resources toward a better pollinated flower, the performance of a worse flower will be underestimated. Although $R$. japonicum could produce fruits by self pollen, 
outcross pollination was important for the reproduction of $R$. japonicum (Fig. 2). Rhododendron species typically suffers from inbreeding depression (e.g., R. brachycarpum, Hirao 2010; $R$. ferrugineum, Delmas et al. 2014).

We initially hypothesized that $B$. diversus queens cannot efficiently pollinate $R$. japonicum because their geitonogamic foraging behaviour would lead to self-pollination. Indeed, $B$. diversus queens visited about six times more flowers in sequence on the same plant than $P$. maackii did. However, fruit set in the bumblebee-dominated area was similar to that in the outcross treatment (Fig. 2); it seems that bumblebees function as pollinators even though $R$. japonicum is only weakly self-compatible (Fig. 2). Because butterfly visits were not completely excluded in the bumblebee-dominated area, the answer of our question (3) (Can $R$. japonicum achieve enough fruit set at sites where bumblebees predominantly visit flowers?) was provisionally "yes". In contrast, in the mixed and time-lag treatments (which were designed to mimic pollination by self and outcross pollen-delivering bumblebee foraging in the wild), fruit set was lower than in the outcross treatment. This result suggests that fertilization by outcross pollen was partly inhibited when self pollen had already been deposited on the stigma. Why then was there the significant difference in the fruit set between the bumblebee-dominated area and the self treatment? First of all, it is possible that four plants of the bumblebee-dominated area had higher selfcompatibility than 40 plants of the open area. Unfortunately, this cannot be verified by our data. Another possibility is that $B$. diversus queens may cause much cross-pollination in the early stage of their stay. Some of the $B$. diversus queens were wearing pollen of $R$. japonicum before visiting the first flower in the videos. Under this condition, cross pollen would preferentially attach to the stigma. Also, the open area included patches with few flower visiting insects, which may cause failure of pollination and consequently, the fruit set in the open area might be not so high $(48.7 \%)$. Considering these results together, we infer that the frequent visits of bumblebees in the bumblebee-dominated area brought large amount of outcross pollen to the flowers and promoted the fruit set, despite the adverse effect of self pollen.

In Japan, Rhododendron species with small flowers such as $R$. semibarbatum Maximowicz (Ono et al. 2008) and $R$. aureum Georgi (Kudo et al. 20II) are pollinated by bumblebees. The result of this study suggests that Japanese Rhododendron species with large flowers can benefit from bumblebee visitation. However, in future studies, seed set of a single flower visit is required to compare pollination efficiency accurately between bumblebees and butterflies (Ne'eman et al. 2010).

As Stout (2007) stated, bumblebee species with small body size do not necessarily match flower shape of Rhododendron, so that stigma contacts depend on their body size. In our observation, the bumblebee workers ( $B$. ardens Smith and B. hypocrita Pérez) collected $R$. japonicum pollen and they were too small to accomplish the pollination of $R$. japonicum. In this respect, an interesting issue for further research is the geographic corolla diameter variation of $R$. japonicum (Takahashi \& Itino 2017). As bumblebee queens and swallowtail butterflies occur in spring to early summer in
Japan while workers are abundant in mid-summer, the geographic variation of flowering phenology $R$. japonicum may synchronize different-sized flower visitors and this may affect regional flower size adaptation of Rhododendron; it may be smaller in the region where small sized flower visitors are abundant. By investigating the factors influencing regional flower size of Rhododendron (e.g., pollinator size, visitation frequencies and behaviour), we will be able to shed light on the role of bees on the evolution of plant flower shapes.

\section{ACKNOWLEDGEMENTS}

We thank the Chubu District Forest Office (Forestry Agency) and the Matsumoto Regional Office (Nagano Prefectural Government) for permission to work in the study areas. This research was supported by the Nagano Society for the Promotion of Science.

\section{REFERENCES}

Chamberlain D, Hyam R, Argent G, Fairweather G, Walter KS (I996) The genus Rhododendron: its classification and synonymy. Royal Botanic Garden of Edinburgh, Edinburgh.

De Jong TJ, Waser NM, Klinkhamer PG (1993) Geitonogamy: the neglected side of selfing. Trends in Ecology \& Evolution 8:32I325 .

Delmas CE, Cheptou PO, Escaravage N, Pornon A (2014) High lifetime inbreeding depression counteracts the reproductive assurance benefit of selfing in a mass-flowering shrub. BMC Evolutionary Biology I4:243.

Epps MJ, Allison SE, Wolfe LM (2015) Reproduction in flame azalea (Rhododendron calendulaceum, Ericaceae): a rare case of insect wing pollination. The American Naturalist I86:294-30I.

Escaravage N, Wagner J (2004) Pollination effectiveness and pollen dispersal in a Rhododendron ferrugineum (Ericaceae) population. Plant Biology 6:606-615.

Fumero-Cabán JJ, Meléndez-Ackerman EJ (2007) Relative pollination effectiveness of floral visitors of Pitcairnia angustifolia (Bromeliaceae). American Journal of Botany 94:419-424.

Goetsch L, Eckert AJ, Hall BD (2005) The molecular systematics of Rhododendron (Ericaceae): a phylogeny based upon RPB2 gene sequences. Systematic Botany 30:616-626.

Herrera CM (1987) Components of pollinator "quality": comparative analysis of a diverse insect assemblage. Oikos 50:79 90.

Hirao AS (2010) Kinship between parents reduces offspring fitness in a natural population of Rhododendron brachycarpum. Annals of Botany 105:637-646.

Huang ZH, Song YP, Huang SQ (2017) Evidence for passerine bird pollination in Rhododendron species. AoB Plants 9:plx062.

Javorek SK, Mackenzie KE, Vander Kloet, SP (2002) Comparative pollination effectiveness among bees (Hymenoptera: Apoidea) on lowbush blueberry (Ericaceae: Vaccinium angustifolium). Annals of the Entomological Society of America 95:345-35I.

Kudo G, Hirao AS, Kawai Y (20II) Pollination efficiency of bumblebee queens and workers in the alpine shrub Rhododendron aureum. International Journal of Plant Sciences 172:70-77.

Mejias JA, Arroyo J, Ojeda F (2002) Reproductive ecology of Rhododendron ponticum (Ericaceae) in relict Mediterranean populations. Botanical Journal of the Linnean Society I40:297 3 II.

Ne'eman G, Jürgens A, Newstrom-Lloyd L, Potts SG, Dafni A (2010) A framework for comparing pollinator performance: effectiveness and efficiency. Biological Revews 85:435-45I. 
Newman E, Manning J, Anderson B (2013) Matching floral and pollinator traits through guild convergence and pollinator ecotype formation. Annals of Botany II3:373-384.

Nilsson LA (1988) The evolution of flowers with deep corolla tubes. Nature 334:147-I49.

$\mathrm{Ng}$ SC, Corlett RT (2000) Comparative reproductive biology of the six species of Rhododendron (Ericaceae) in Hong Kong, South China. Canadian Journal of Botany 78:22I-229.

Ono A, Dohzono I, Sugawara T (2008) Bumblebee pollination and reproductive biology of Rhododendron semibarbatum (Ericaceae). Journal of Plant Research I2I:319-327.

R Core Team (2017) R: A language and environment for statistical computing. R Foundation for Statistical Computing, Vienna, Austria. Available from https://www.R-project.org/

Stang M, Klinkhamer PG, Waser NM, Stang I, van der Meijden E (2009) Size-specific interaction patterns and size matching in a plant-pollinator interaction web. Annals of Botany I03:I459I469.

Stevens PF (1985) Malesian Vireya rhododendrons-towards an understanding of their evolution. Notes from the Royal Botanic Garden Edinburgh 43:63-80.

Stout JC (2007) Pollination of invasive Rhododendron ponticum (Ericaceae) in Ireland. Apidologie 38:198-206.

Takahashi K, Itino T (2017) Visitation frequencies of bumblebees and swallowtail butterflies to flowers and the nectar sugar concentration of Rhododendron kaempferi and $R$. japonicum in mountains of central Japan. Journal of Pollination Ecology 2I:9I97.

Waser NM, Chittka L, Price MV, Williams NM, Ollerton J (1996) Generalization in pollination systems, and why it matters. Ecology 77:1043-1060

Yamazaki T (1996) A revision of the genus Rhododendron in Japan, Taiwan, Korea and Sakhalin. Tsumura Laboratory, Tokyo. 